\title{
On the Wall-effect of a Nucleus-counter
}

\section{S. Ohta}

It was found out that a thin boundary layer in which no fog is formed exists along the wall surface of the cloud chamber, when dusty air is taken into the chamber and expanded with expansion-ratio of about 1.2. The mean thickness of this boundary layer, which was measured with a microscope in vayious ways (see figure), was $0.25 \mathrm{~mm}$.

The thickness seemed to be related to the speed of the expansion. The above figures were observed when the speed of expansion was about $0.03 \mathrm{sec}$. When the speed was slow as in the case of nucleus counting, the thickness increased becoming $0.4 \sim 0.8 \mathrm{~mm}$.

The formation of this layer seemed to be explained by the thermal conduction from the wall and also by the decrease of density of water vapour in the chamber due to expansion.

The above phenomena, the wall-effect, have a great important role in the theory of masurement, of nuclei. Due to the existence of such a layer, it is true that nuclei fallen on a glass plate are not the entire nuclei that exist in the chamber, i.e. nuclei included in the layers near the glass plates may be left unchanged into drops.

Thus we have to repeat expansions successively on the same sample of air in order to find out the total number of nuclei in the chamber.

Assuming the thickness of the layer, the number of drops that falls at each stage of expansion was theoretically calculated and the result was compared with the observed values obtained by J. J. Nolan, G. R. Wait and other workers. It was proved that number of drops caught in each expansion seemed to be explained mostly by the existence of the layer.

(Dec. 1947)

\section{地面附近の大氣の讑㞦（第 3 報）}

籃 谷 正 雄*

\section{\$1. 氣溫の戀動について}

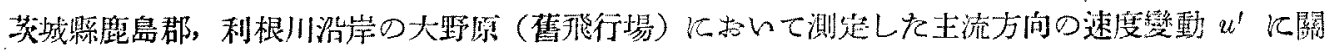

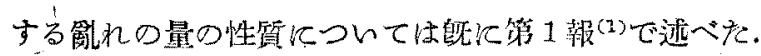

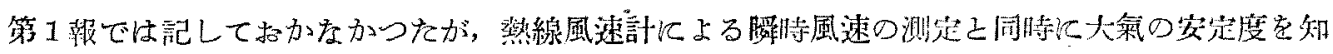

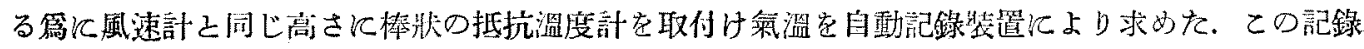

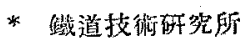

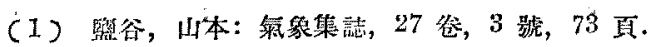




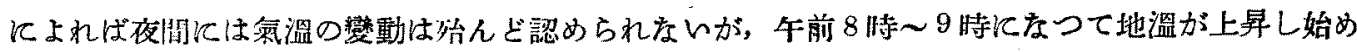

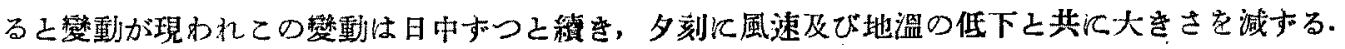
以上は啨天の際に云えることであつて，日中でも厤雲が全天を蔽つている時恃氣溫の變動は始んぞ 衿められない。

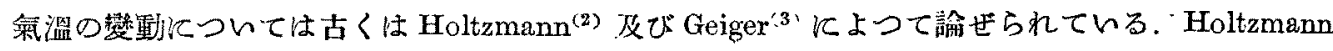

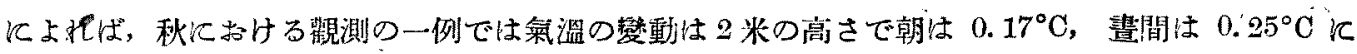

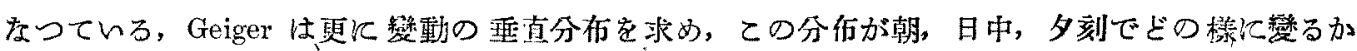
述べている.

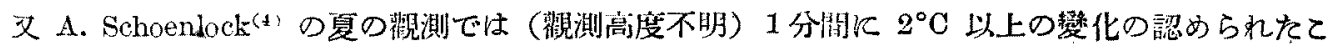

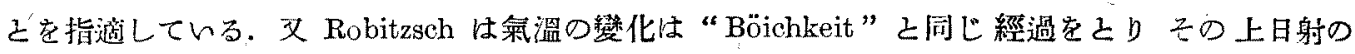

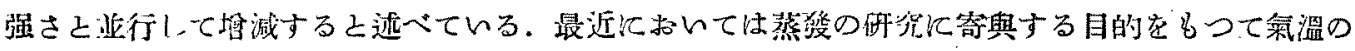
變動を求めをものや (Ameri. Geophys. Union, Trans. 1 (1943), 又 micro wave の下僱大氧中の

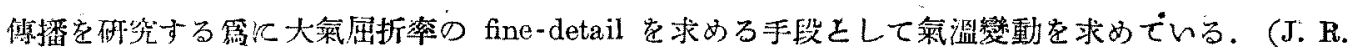
Gerhardt \& W. E. Gordon: Jour. Met., 5, 197 (1948).

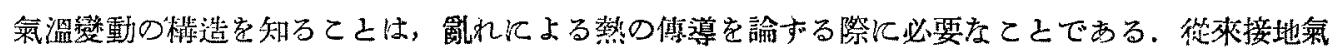

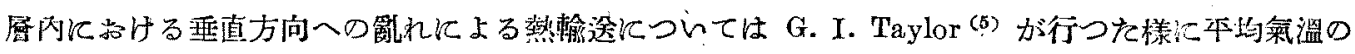

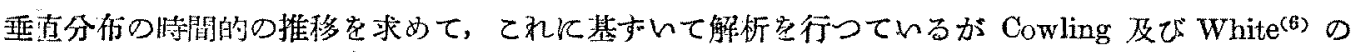

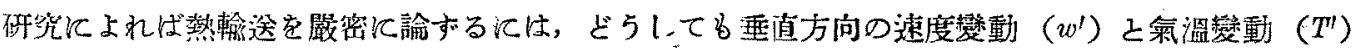

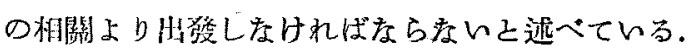

以後の議論では氣溫の變動に關聯する請現象を氣溫の獣れ之呼ぶこ之にし，その棈造，及び風速 日射量との關聯等沉つんて还べ。.

\section{\$2. 測 定 法}

氣溫の瞬時位の測定を行5には抵抗溫度計を用らるここにし，その抵抗溫度計の指示を電掽オッ シログラブを用レて連續的飞記錄させを。

\section{(1) 抵抗溫度計。}

溫度計はなるへく time lag 家小さ?する篇に直徑 0.04 䬿, 長さ約 40 糎の裸の 2本のニッケ ル線を溫度計素子とし，との線を第 1 圖に示す樣に舊式のタングステン電琲の線條の栐に，キッグ

(2) M. J. Holtzmann: Meteor. Z., 53, 329 (1936).

(3) Geiger: Meteor. Z., 54, 278 (1937).

(4) A. Schoenlock: Meteor. Z., 53, 329 (1936).

(5) G. I. Taylor: Phil. Trans. Roy. Soc. London, A, 215 (1915).

(6) T. Cowling and A. Whit: Q. J. Roy. Met. Soc., 67, 276 (1941).

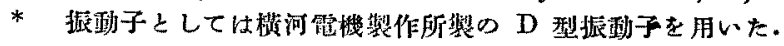




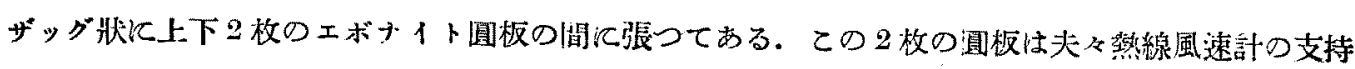

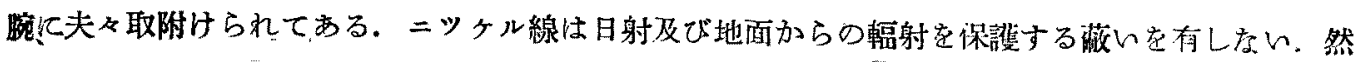

第 1 回

(a)

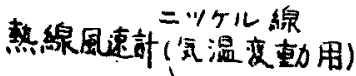
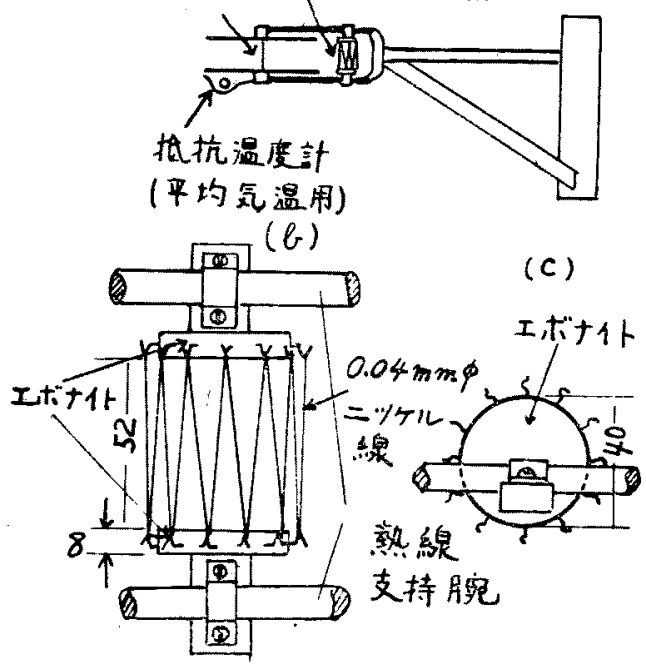

(a) Hot wire anemometer and resistance thermometer. (b), (c) Detail of resistance thermometer for measuring fluctuations of air temperature.
し線(7)の直徑が細く，装面が兆澤を有する㻛合は 輻射の影慗を受けることが少いここが磪かめられ ている.

(2) 測起可路及び氣温の求め方.

上記の抵抗溫度計を第 2 圖の樣にホイートスト

$$
\text { 第 } 2 \text { 圆 抵抗溫度䛎 }
$$

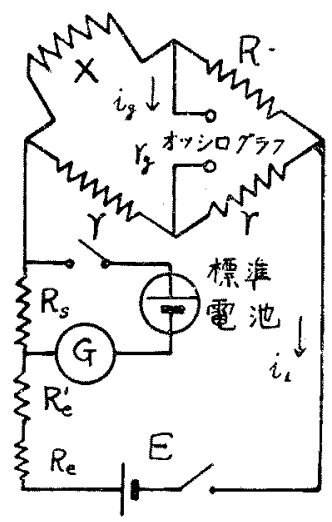

Electric circuit for measuring fluctuation of air temperature.

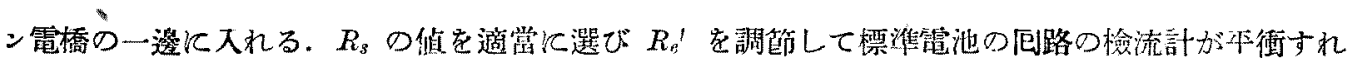

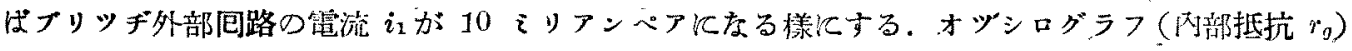
流れる電流 $i_{9}$ そ $X$ との關係はキルヒホッフの式より

$$
X=R\left[1+\frac{i_{g}}{i_{1}}\left(\frac{r+R+2 r_{g}}{R}+\frac{r+R+2 r_{g}}{r}\right)\right]
$$

となり $i_{1}$ は一定であるから $\left(R_{e} \gg X, R, r\right) i_{g}$ の值より $X$ が求をる.

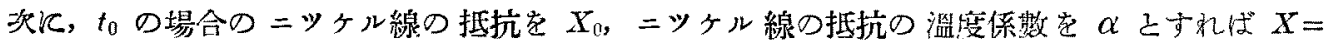
$X_{0}\left(1+\alpha\left(t-t_{0}\right)\right)$ である. 從つて求方る溫度 $t$ は

$$
t=t_{0}+\left(X-X_{0}\right) / X_{0} \alpha
$$

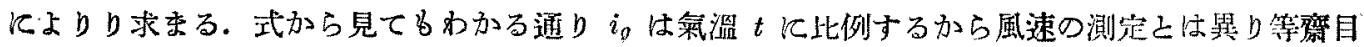
盛が得られる。

(7) A. Albrecht: Meteor. Z., 44, 421 (1927). 


\section{\$6. 氣盢測定の際に含まれる誤差}

\section{（1）風任化上る誤差}

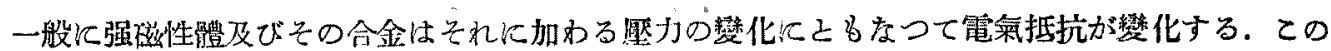
原理を䏳々て张力計（strain sensitive resiatance meter）は米國では賽用されている。抵抗溫度計

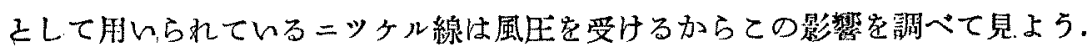

風速 $V$ の氣流中浱られたニッヶル線の受ける企王は $d / 2 \cdot \rho V^{3} c_{D}$ 亿よつて與えられる。但し $l$ 及び $d$ は夫之線の艮さ及び直俓， $c_{D}$ は抗力係數で Reynold's 数が 20 から 30 の時約 2.0 の

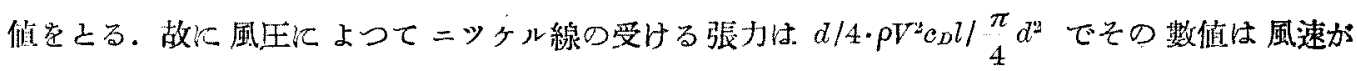
$20 \mathrm{~m} / \mathrm{sec}$ の特 $1.0 \times 10^{6} \mathrm{dyn} / \mathrm{cm}^{2}$ である，他方磁場の無い状態ではニッヶル線に加わる張力が $2 \mathrm{~kg} /$ $\mathrm{mm}^{2}$ の之きは之の抵抗揫化 $\Delta R$ は元の抵抗值 $R$ の約 0.01 倍である。從つて我々の場合は $\Delta R$

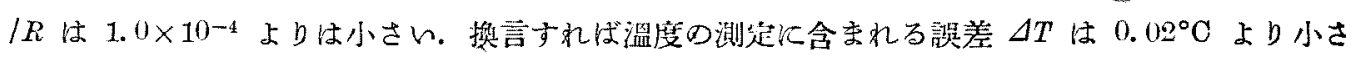
くなり，賽測值水は影響を及快ざい。

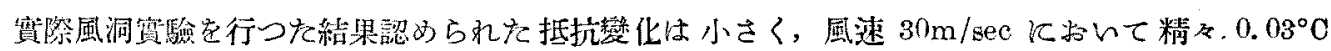
の愦差を生方る程度であつた。

\section{（2）日射及び自己加熱による㛊差}

太陽上りの輻射柱大部分二ッタル線琵面上り反射されるが，一部は吸收されて線の溫度を上年さ

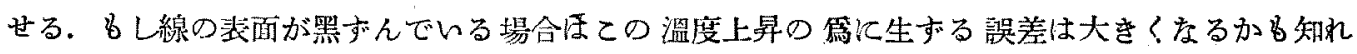
ない。

線の溫芰を $\theta$, 㴋溫它 $\theta_{0}$, , 線の表面の熱傅達率を $b$, 線の單值表面の受ける輻射量を $q$, 線の比

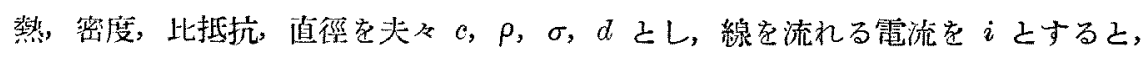

$$
\frac{d \theta}{d t}=\frac{16 i^{2} \sigma}{\dot{\pi}^{2} d^{4} \rho c}+\frac{4 k q}{\rho_{c d}}-\frac{4}{\rho_{c} d} b\left(\theta-\theta_{0}\right)
$$

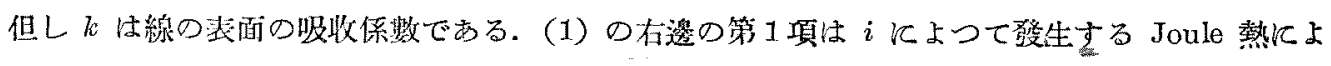
る項，第 2 項は線儿吸收される輻射熱儿上る項，第 3 項は强帅對流に上り熱線表面上り奪われる熱

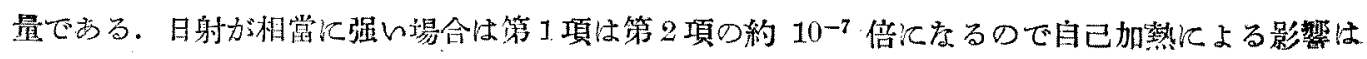
無視收來る。

$$
\text { さて, } r=r_{0}\left(1+\alpha\left(\theta-\theta_{0}\right)\right) \text { 及び(8) } b=0.6 \frac{\lambda}{4}\left(\frac{v d}{\nu}\right)^{04} \text { である.こよで } r \text { 及び } r_{0} \text { は } \theta \text { 及び } \theta_{0} \text { の }
$$

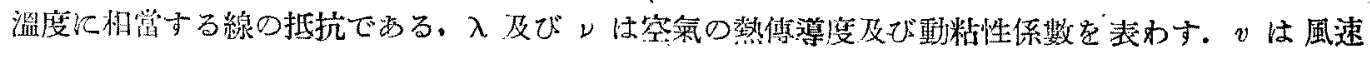

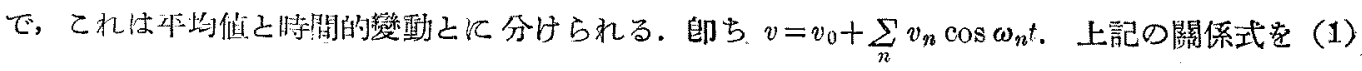
に入れるよ

\footnotetext{
(8) Hilpert: Forschung, 4, 215 (1933).
} 


$$
\frac{1}{r_{0} \alpha} \frac{d r}{d t}=\frac{4 k q}{\rho c d}-\frac{2.4}{\rho e d} \frac{\lambda}{d}\left(\frac{v_{0} d}{\nu}\right) \cdot 4\left(1+0.4 \sum_{u} \frac{v_{n}^{\prime}}{v_{0}} \cos \omega_{n z} t\right)_{r_{0} \alpha}^{r-r_{0}}
$$

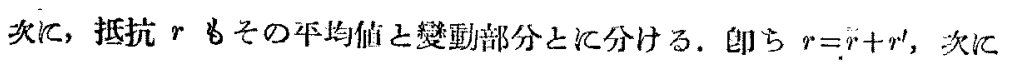

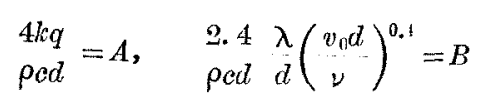

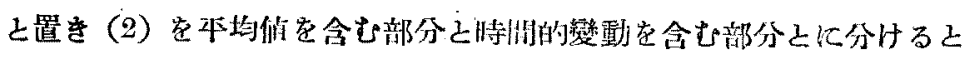

$$
\begin{gathered}
r_{0} \alpha A=B\left(\bar{r}-r_{0}\right) \\
\frac{d r^{\prime}}{d t}+B r^{\prime}+0.4 B\left(\bar{r}-r_{0}\right) \sum_{n} \frac{v_{n}^{\prime}}{v_{0}} \cos \omega_{n} t=0
\end{gathered}
$$

(3) $上$

$$
\bar{\theta}-\theta_{0}=\frac{A}{B}=k q / 0.6 \frac{\lambda}{d}\left(\frac{v_{0} d}{\nu}\right)^{0.4}
$$

そなる. (4) の数值として $k=0.4, q=0.025 \mathrm{cal} / \mathrm{cm}^{2} \cdot \mathrm{sec}, d=0.003 \mathrm{~cm}, \lambda=6.0 \times 10^{-5} \mathrm{cal} / \mathrm{cm}$. sec ${ }^{\circ} \mathrm{C}, \nu=0.15 \mathrm{~cm}^{2} / \mathrm{sec}\llcorner\mathrm{L}$

$$
v_{0}=\left\{\begin{array}{c}
1 \mathrm{~m} / \mathrm{sec} \\
10 \mathrm{~m} / \mathrm{sec}
\end{array} \text { 汇龂して } \bar{\theta}-\theta_{0}=\left\{\begin{array}{r}
0.63^{\circ} \mathrm{C} \\
0.25^{\circ} \mathrm{C}
\end{array}\right. \text { となる. }\right.
$$

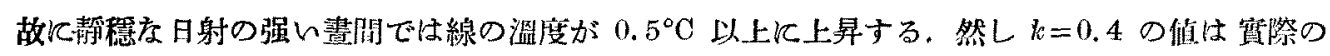

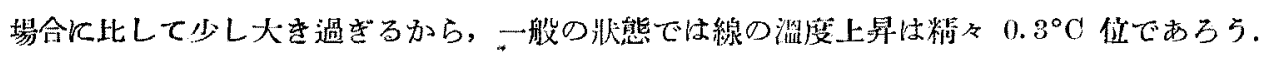

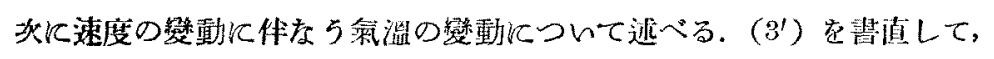

$$
\frac{d r^{\prime}}{d t}+\frac{r_{0} \alpha A}{\bar{r}-r_{0}} r^{\prime}=\sum_{n} 0.4 r_{0} \alpha A g_{n} \cos \omega_{n} t
$$

こさで $g_{n}=v_{n}{ }^{\prime} / v_{0}$ である.さて $r_{n} \alpha A /\left(\bar{r}-r_{n}\right)=M$ 及げ $0.4 r_{n} \alpha A g_{n}=P_{n}$ 亡する. (5) は

$$
\frac{d r^{\prime}}{d t}+M r^{\prime}=\sum_{n} P_{n} \cos \omega_{n} t
$$

之畫換えられる. $\left(5^{\prime}\right)$ の解は

$$
r^{\prime}=c e^{-M t}-\sum_{n} \frac{P_{n}}{M \sqrt{1}+\left(\omega_{n} / M\right)^{2}} \cos \left(\omega_{n} t-\phi_{n}\right), \quad \phi_{n}=\tan ^{-1} \frac{\omega_{n}}{M}
$$

となる. $1 / M$ は恃定数で $1 / M=\left(\ddot{\theta}-\theta_{0}\right) \cdot \rho e d / 4 k q$ で琵わされ，その数值は風速 $1 \mathrm{~m} / \mathrm{s}$ で 0.06 秒

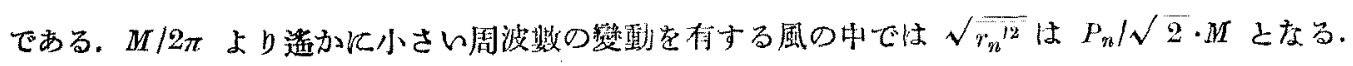
故㳊 $\sqrt{\overline{r_{n b}{ }^{\prime 2}}} / \bar{r}=0.4 \alpha g_{n}\left(\bar{\theta}-\theta_{0}\right)$ 乙度る。

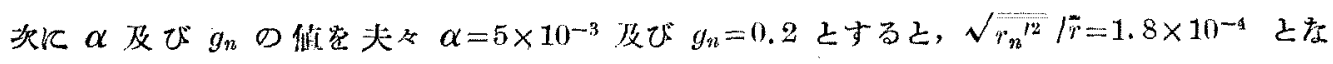

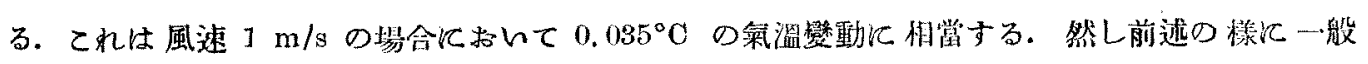

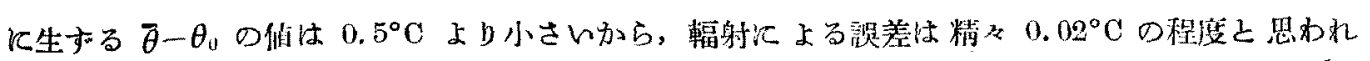
3. 
（3）線の㭙間の退れによつて生ずる䛇差

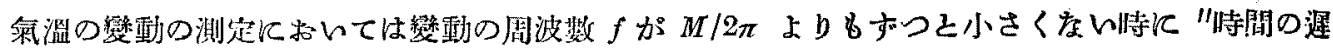

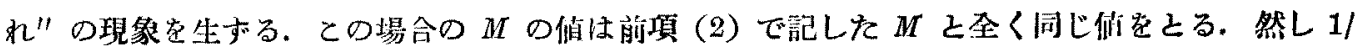
$M=0.06$ 秒怙大を過を゙る。普通の伙態では $\left|\vec{\theta}-\theta_{0}\right|$ は $0.3^{\circ} \mathrm{C}$ 上り小さんてとから考えて $1 / M$

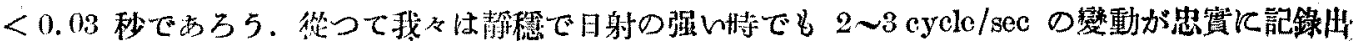
承る。

\section{\$4. $\boldsymbol{T}^{\prime}$-分布. $\sqrt{\overline{\boldsymbol{T}^{\prime 2}}}$ の大きさ及び垂直分布}

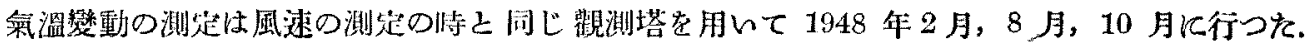
2 月で性上高 15 米迄行い得てが，其の

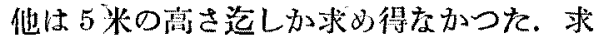
められを記錄を 240 秒の閒 0.4 秒藕に僢

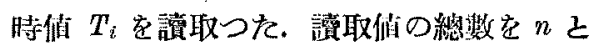
すれば，本均倠 $\bar{T}=\sum_{0}^{n} T_{i} / n$ によて定袐 される．解析を行う記錄としてはての赫告 においては睛天の日中に得られた斥の小 に限ることにする。

瞬恃倠之平均做之の差 $T^{\prime}\left(=T_{i}-\bar{T}\right)$ の 分布は一般江正規の Gauss 分们である。こ れを第 3 圖炕示す. 圆中の Feb. 10 th の $T^{\prime}$ の Histogram が示している漛に，分布曲 線の最大值が低溫部にあり，曲線の傾斜が 高溫部の㘯に伸びているととがある。この 型の分布は冬季 3 米以上の高さの氯曆內で のみしか見られボ， 3 米以下及び夏零 5 米 の高さ迄の䚋澌では分们の型は Gauss 分

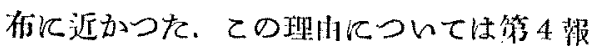
において述べろととにする。

$\sqrt{ } \sqrt{T^{\prime 2}}$ の大きさは第1表沉記しておる。

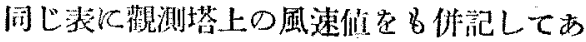

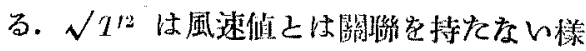
である。一般に $\sqrt{7^{2}}$ の大きさは 1 米の离

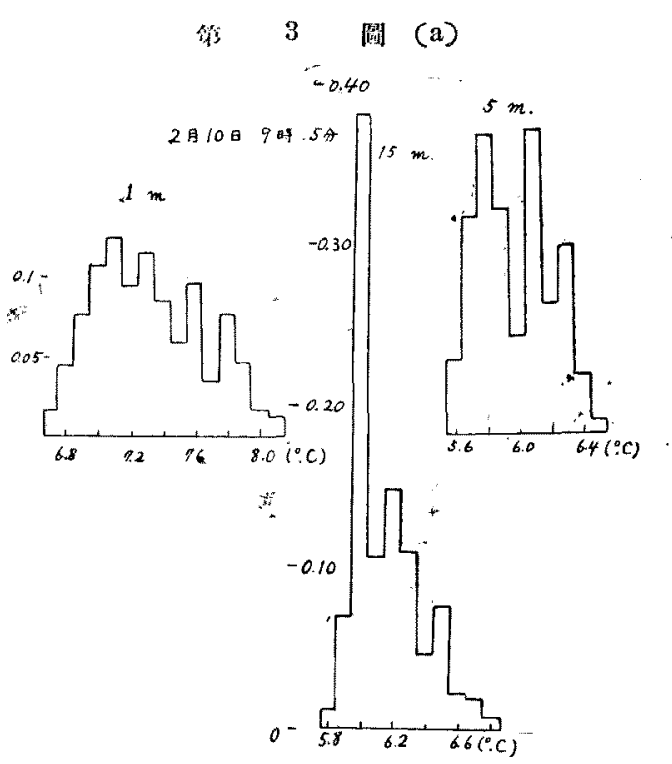

Frequency distribution of $T^{\prime}$

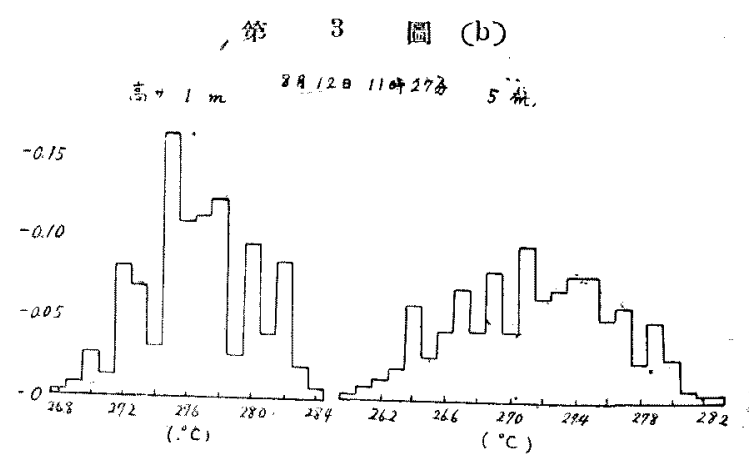

Frequency distribution of $T{ }^{\prime}$ 
第 1 表

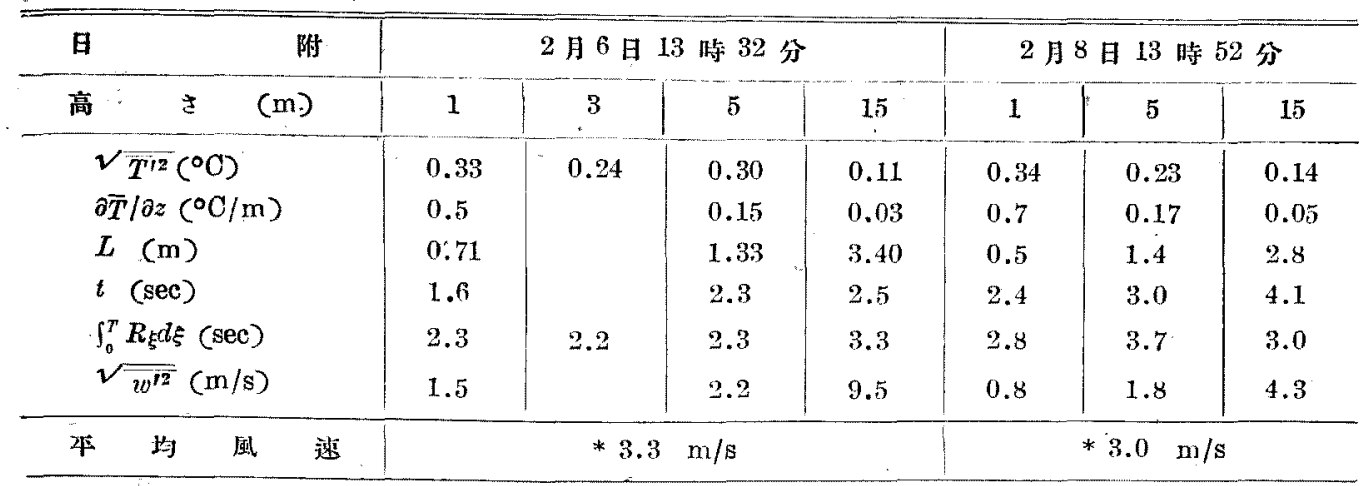

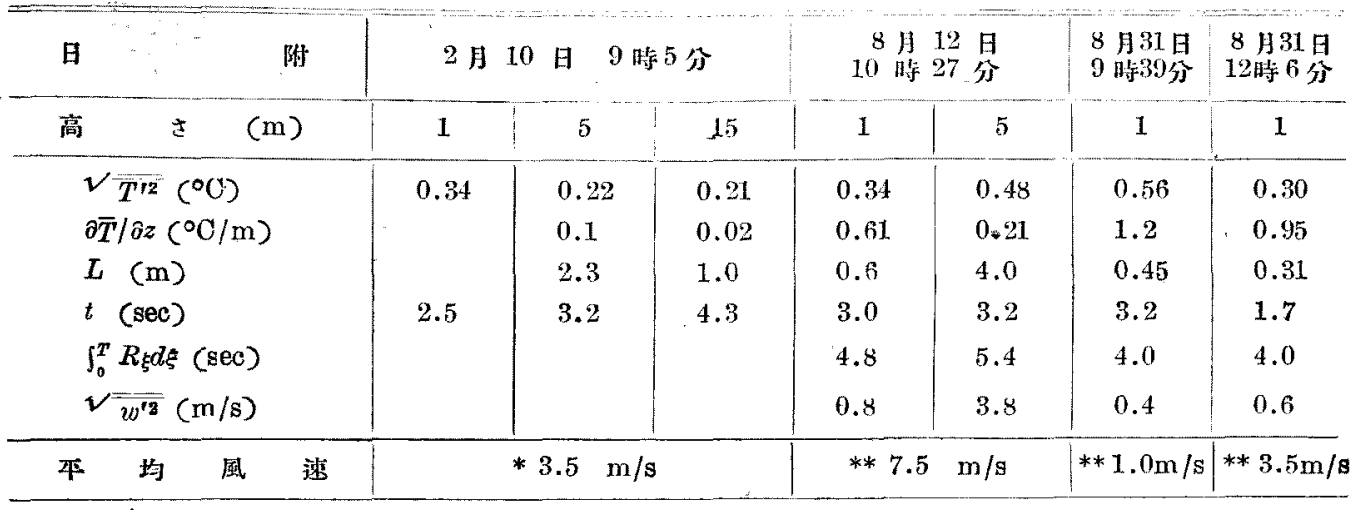

[注 意] * 高さ 16 米の平均風速值, **高さ6 米の本均風速值,

さでは $0.3 \sim 0.4^{\circ} \mathrm{C}$ であり，15米の高さでは $0.2 \sim 0.1^{\circ} \mathrm{C}$

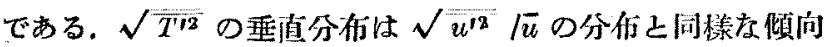

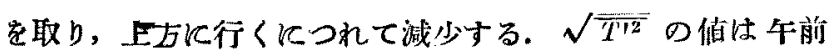

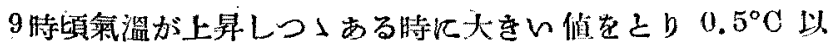
上にも僬している. 第 1 節に記した Holtzmann ${ }^{(2)}$ の值 0.25 ${ }^{\circ} \mathrm{C}$ は我々の場合に比して少し小さんが，乙れ待が䫏測に 使用した Assmann $の$ 通風溫度計は我々の場合に比して time $\operatorname{lag}$ が大をいからであら5.

オッシロダラフの記錄を見ると，温度の方が風速よりも迅

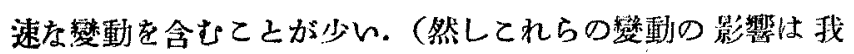
くの解析による 0.4 秒每の譠取りでは䊼果には直接们入つ ててない.) 又氣溫の愁動には風の息に相虽する㧼存 $30 \sim 40$ 保 4 践

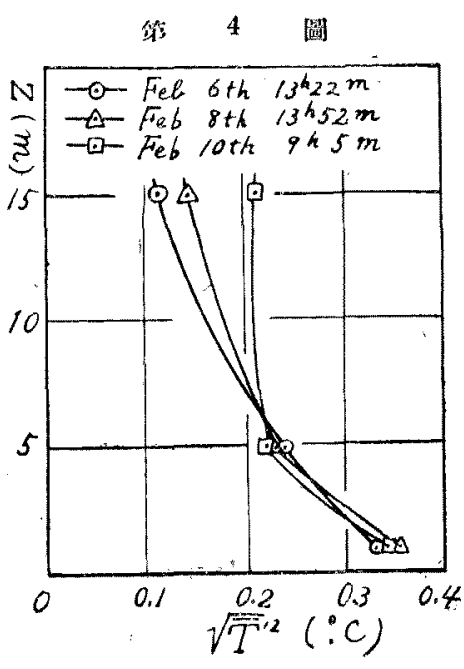

Vertical distribution of $\sqrt{T^{\prime 2}}$

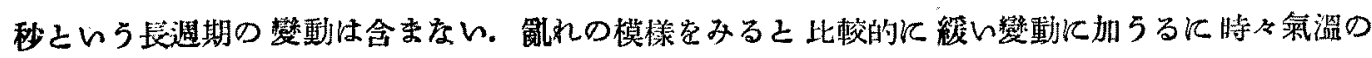




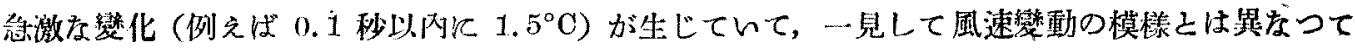
ทる.

\section{ミ5. 氣溫楚動の相關及び镝れれの尺度}

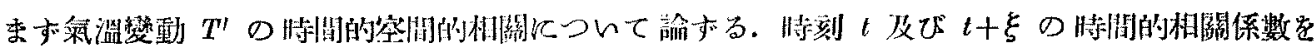
$R_{\xi}$ で表わして狄を第 4 圖に示す。曲 第 5 圆（a)

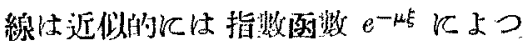

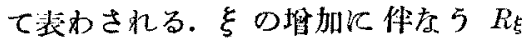
の減少の割合数風速の相緊の措合上り 大きく， $R_{\xi}$ がグラフ上で 點炕相當する $\xi$ の諙は 8〜16 秒で $\xi$

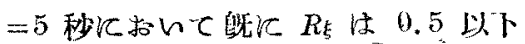
である。

次江垂直方向飞 $y$ だけ離れている

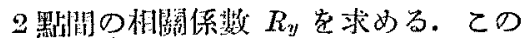
值は第 2 表化示してある. $R_{y}$ は $y=$

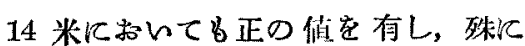
Feb. 10 th, $9 \mathrm{~h}, 5 \mathrm{~m}$ の樣淿地溫が上 昇しつ১するときは $\sqrt{T^{\prime 2}}$ の倾之闰

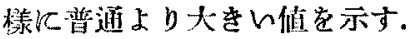

$R_{\xi}$ の位より $\overline{T^{2}}$ のスペクトル分后 が風速 $u^{\prime 2}$ の之き之同情化L.て求めら れる筈で要る， $R_{\xi}$ の曲線の型上り楙

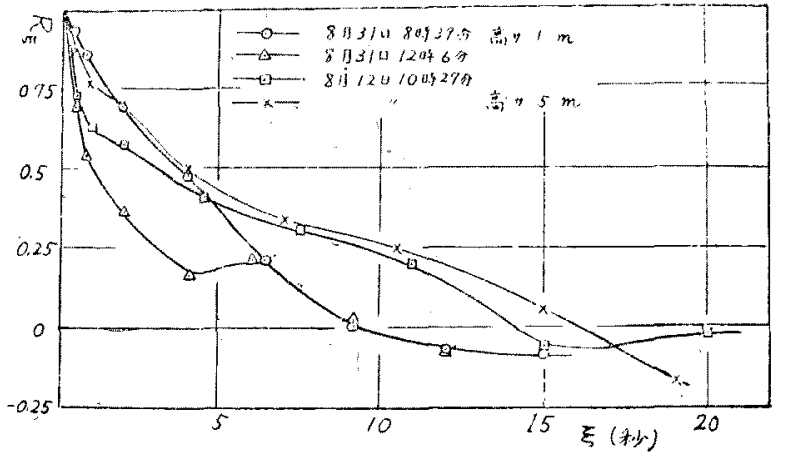

Timely correlation of fluetuation of air temperature 第 5 圖 (b)

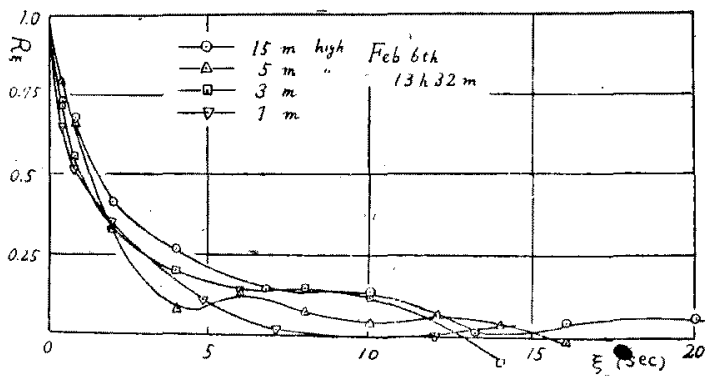

Tinely correlation of fluctuation of air temperature

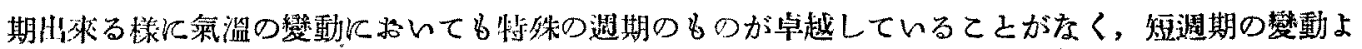

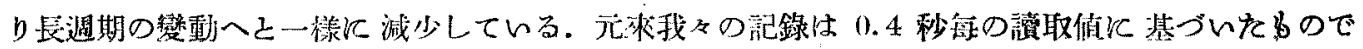

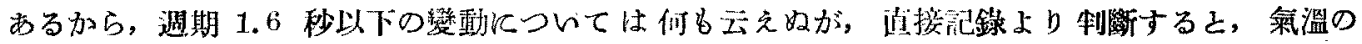
第 2 表 $R_{\|}$相關保數

\begin{tabular}{c|c|c|c|c|c|c|c|c|c|c|c|c|c|c|}
\hline $\begin{array}{c}\text { 高 } \\
\mathrm{a}(\mathrm{m})\end{array}$ & 15 & 5 & 3 & 1 & 15 & 5 & 1 & $* 15$ & 5 & 1 \\
\hline 15 & 1 & 0.42 & 0.29 & 0.16 & 1 & 0.26 & 0.11 & 1 & 0.69 & 0.57 \\
5 & & 1 & 0.46 & 0.36 & & 1 & 0.49 & & 1 & 0.71 \\
3 & & & 1 & 0.39 & & & & & & &
\end{tabular}

2 月 6 日 13 晴 32 分

2 月8 日 13 時 52 分 2 月 10 日 9 㭙 5 分 


\begin{tabular}{|c|c|c|c|c|c|c|c|c|c|c|c|c|c|c|c|}
\hline $\begin{array}{l}\text { 高 } \\
(m) \\
(m)\end{array}$ & 5 & 3 & 2 & 1 & 0.6 & 5 & 3 & 2 & 1 & 0.6 & 5 & 3 & 2 & 1 & 0.6 \\
\hline 5 & 1 & 0.51 & 0.14 & & 0.70 & 1 & 0.67 & 0.44 & & 0.46 & 1 & 0.21 & 0.66 & * & 0.05 \\
\hline 3 & & 1 & 0.58 & & & & 1 & 0.57 & & & & 1 & 0.28 & & \\
\hline 2 & 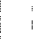 & & 1 & 0.76 & 0.76 & & & 1 & 0.78 & 0.75 & & & & 0.54 & 0.25 \\
\hline 1 & & & & 1 & 0.71 & & & & 1 & 0.76 & & & & 1 & 0.18 \\
\hline
\end{tabular}

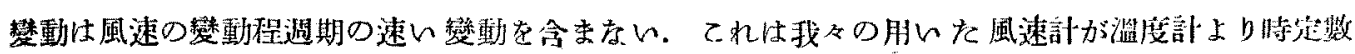

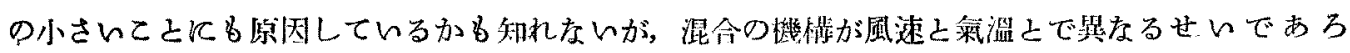
5.

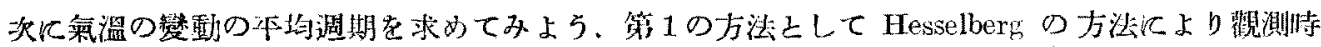

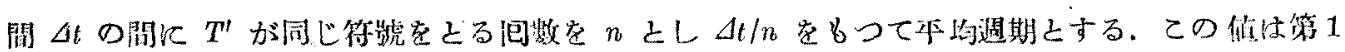

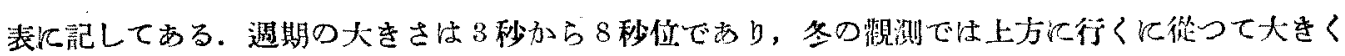
るるが，夏は垂淔方向の變化は明隌江現かれない。

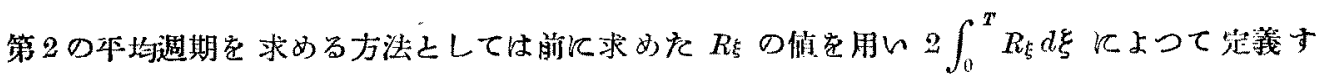
る.乙よで $T$ は $R_{\xi}$ がグラフ上で $\xi$ 軸を切る點沉相應する $\xi$ の值である.乙の值は第 1 表に示

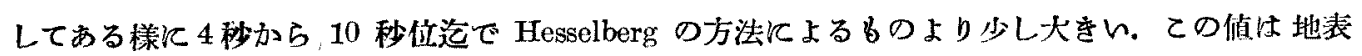
溫度が坦すにつれて大きくなつている。

さて高さ $z$ なる場所の平均氣溫及び氣溫彪減率を夫ょ $z ー l$ にあつた氣塊が，その位置にある熱量を保持しながら，垂值上方に動を $z$ なる默を通過した

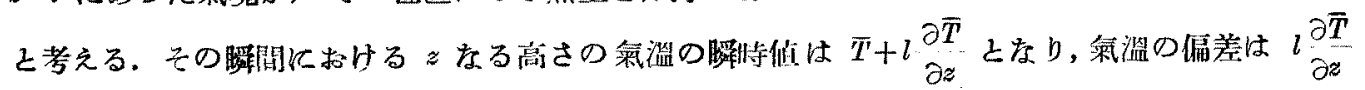

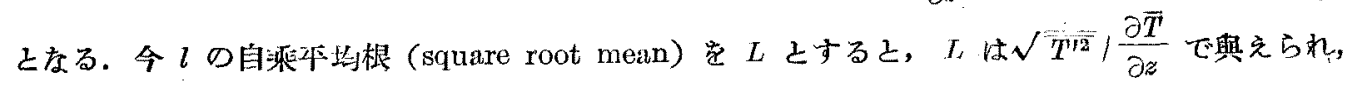

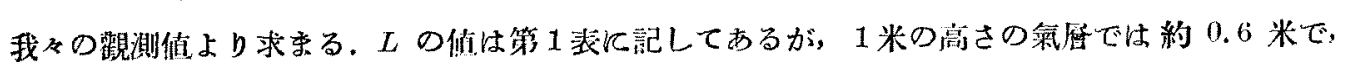
氣愿の高さが坦すにつれて大さくなつている.

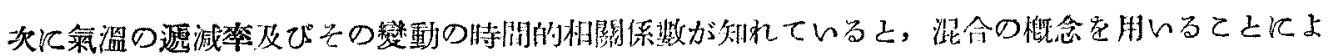

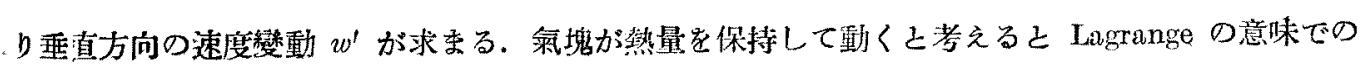
$d T / d t$ 恃零之なる。一方

$$
\frac{d T}{d t}=\frac{\partial T}{\partial t}+u \frac{\partial T}{\partial x}+v \frac{\partial T}{\partial y}+w \frac{\partial T}{\partial z}
$$

であり， $\frac{\partial T}{\partial x} \cdot \frac{\partial \boldsymbol{T}}{\partial y}$ を $\frac{\partial \boldsymbol{T}}{\partial z}$ そ比して热視すると

$$
\begin{gathered}
-\frac{\partial T}{\partial t}=w^{\prime} \frac{\partial T}{\partial z} \\
-37-
\end{gathered}
$$


故江近似的保

$$
\sqrt{\overline{w^{\prime 2}}}=\sqrt{\left(\frac{\partial T^{\prime}}{\partial t}\right)^{2} / \frac{\partial \bar{T}}{\partial z}}
$$

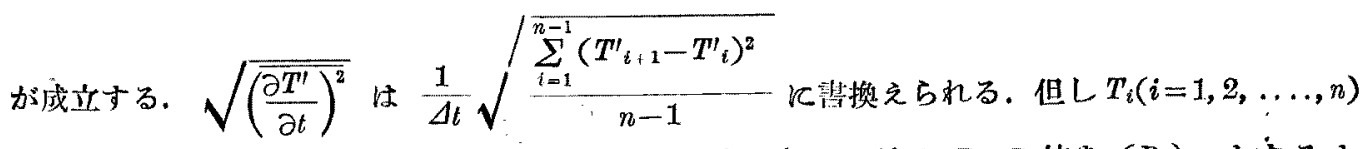

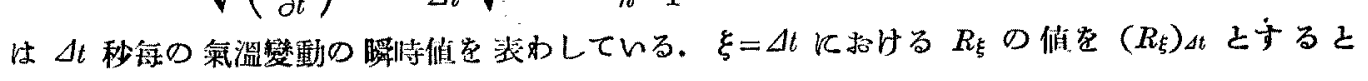
$\sqrt{\left(\frac{\partial T^{\prime}}{\partial t}\right)^{2}}$ は更に $(\sqrt{2} / \Delta t) \cdot \sqrt{1-\left(R_{\xi}\right)_{\Delta t}} \cdot \sqrt{\overline{T^{\prime 2}}}$ となる. 從つて

$$
\sqrt{\overline{w^{\prime 2}}}=\frac{\sqrt{2}}{\Delta t} \cdot \sqrt{1-\left(R_{\xi}\right)_{\Delta}} \cdot \sqrt{T^{\prime 2}} / \frac{\partial \bar{T}}{\partial z}=\frac{\sqrt{2}}{\Delta t} \sqrt{1-\left(R_{\xi}\right)_{\Delta t}} \cdot L
$$

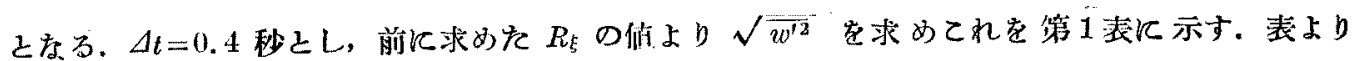

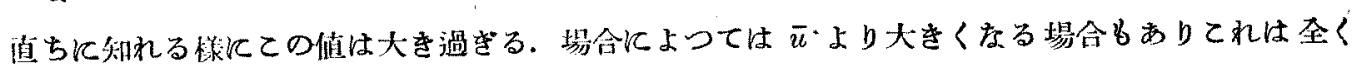

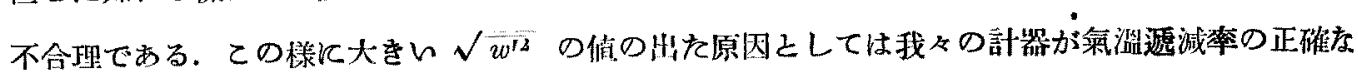
值を求めるのに不適當なのかる知れないが, 恐らく氣溫の變動は小氣塊の不規则運動上り生する混

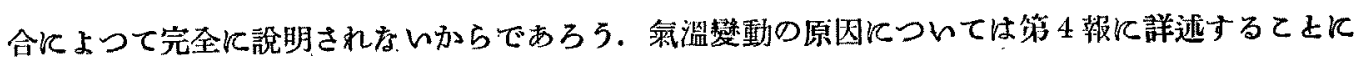
する。

（昭和 25 年 1 月 28 日受理）

\section{Turbulence in the Lowest Layer of the Atmosphere}

(Fluctuations of air temperature and their related phenomena)

\section{Shiotani}

Fluctuations of air temperature in the air layer up to 15 meters above the ground were measured by resistance thermometers (which were made of bare nickel wire, $0.03 \mathrm{~mm}$ in diameter and about $80 \mathrm{~cm}$ long, stretched in the space without protecting cover). This thermometer was inserted in one arm of a Wheatstone bridge and the unbalanced current was lead to an electromagnetic oscillograph. The errors that occur in the measurement are discussed. They consist of those induced by the wind pressure, insolation and time lag of the thermometer. Their magnitudes are generally' less than $0.04^{\circ} \mathrm{C}$, on the other hand fluctuations of temperature are about $0.4^{\circ} \mathrm{C}$. So, errors described above are negligible in the

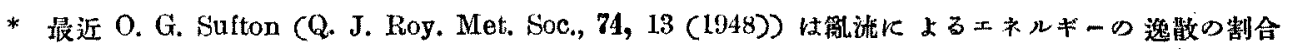

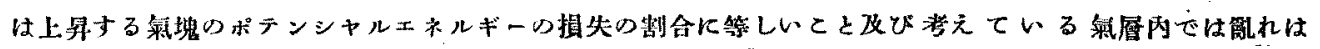
等方性であるといら假定より $\sqrt{w^{\prime 2}}=$ const $L \sqrt{-\frac{g}{\theta} \frac{\partial \theta}{\partial z}}$ そい5關保を地上高7 7 45m の氣啳内でみ ちびいた。 
mensurement of temperature fluctuation. The magnitude of fuctuations of air temperature is $0.3 \sim 0.4^{\circ} \mathrm{C}$ in the air layer 1 meter above the ground and the magnitude decreases to $0.2 \sim 0.1^{\circ} \mathrm{C}$ in the air layer 15 moters above the ground. Timely and spacial correlations of air temperature fluctuations $\left(R_{\xi} \overrightarrow{\mathrm{and}} R_{y}\right)$ are obtained. $R_{\xi}$ is expressed approximately by the exponential cyrve $e^{-\mu t}$, and the magnitude of $2 \int_{0}^{T} R_{\xi} d \xi$ is about $8 \sim 16$ sec. (where $T$ is the value of $\xi$ at which $R_{\xi}$ first cuts the $\xi$-axis.) $R_{y}$ is positive even at $y=14$ meters. The values of correlation are larger than usual when the air temperature of the ground is increasing rapidly. It is discussed that fluctuations of temperature are not wholly due to the mixing phenomena ( $i$. e. the random motion of the lump of air).

\section{雷雨中の窒素化合物含有量の時間的 變化とその成因}

新海滕良*

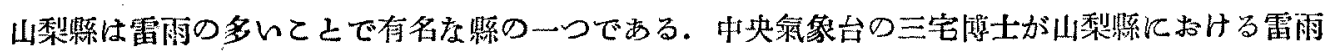

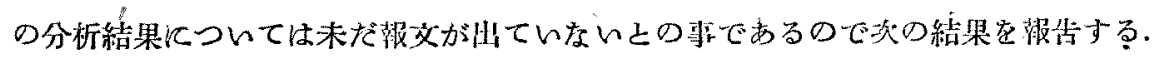

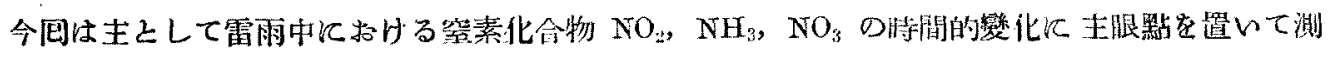
䇥し，その結果加らそれらの成因についても推論した。

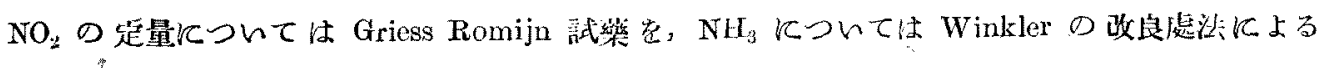
Nessler 試㣺堂用いた.

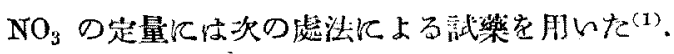

$$
\begin{aligned}
& \text { メーナフチルアミン } 1 \mathrm{~g} \\
& \text { スルファニル酸 } 10 \mathrm{~g} \\
& \text { 㱚一鉛 根 } 1 \mathrm{~g}
\end{aligned}
$$

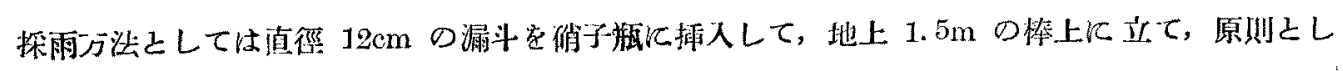

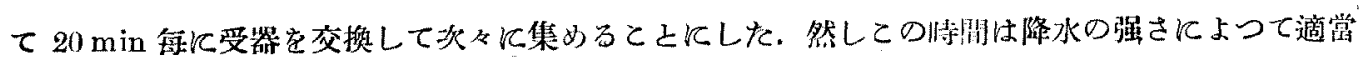
に繁えた。

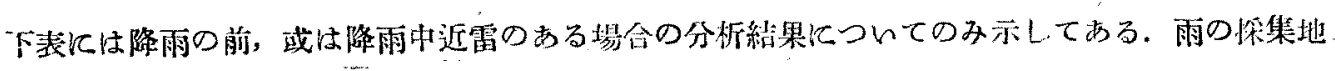

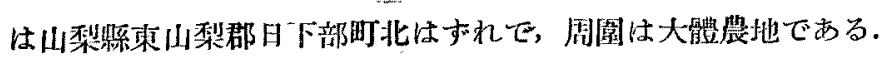

な持表中，亞硝酸，确酸及びフンモニアの何れ含量は等素之して計算した。

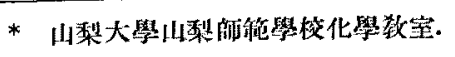

